\title{
UM EPIGRAMA DE MARCIAL NA TRADUÇÃO DE J. F. DE CASTILHO: ENSAIO DE ANÁLISE BERMANIANA
}

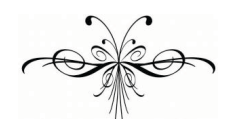

JOANA JUNQUEIRA BORGES

\begin{abstract}
Resumo: Através da analítica da tradução oferecida por Antoine Berman (2007), oferecemos neste artigo um ensaio de análise das escolhas tradutórias de José Feliciano de Castilho (18101879) em sua tradução do epigrama I, 71 de Marcial.
\end{abstract}

Palavras-chave: Antoine Berman, José Feliciano de Castilho, Marcial, Tradução de poesia.

\section{Tradutor, texto de partida e texto de chegada}

$\mathrm{T}$ em havido em nossas letras um crescente interesse em se constituir uma história da tradução dos clássicos greco-romanos para a nossa língua como se verifica nos trabalhos de Haroldo de Campos na década de setenta com seus estudos sobre as traduções de Odorico Mendes (1799-1864), de Antônio Medina Rodrigues, que trabalhou com os versos de Homero traduzidos por Odorico (1992) e de Paulo Sérgio de Vasconcellos, que coordena um grupo preocupado em compilar e atualizar a ortografia, bem como anotar e comentar as traduções de Odorico, o que já foi realizado com as Bucólicas e Eneida (VIRGÍlLIO, 2008a e 2008b). No entanto essas retomadas das traduções de Odorico não são as únicas preocupadas com a recepção dos clássicos em nossa língua, traduções do século XVIII e XIX como os excertos de Bocage das Metamorfoses de Ovídio foram reeditados em 2007 e uma versão da Eneida de José Victorino Barreto Feio foi publicada em 2004, ambas sendo impressas aqui no Brasil e marcando a atenção que tem sido dispensada aos clássicos pelo mercado editorial brasileiro.

Pensando em contribuir com a pesquisa de traduções lusófonas dos clássicos greco-romanos e com a recepção desses textos, apresentaremos neste artigo resultados preliminares de nosso trabalho, que procura inventariar, estudar e divulgar a obra tradutória de José Feliciano de Castilho, distinto português que viveu no Rio de Janeiro de 1847 até sua morte em 1879, sendo produtor de uma vasta obra de filólogo, latinista e tradutor de latim. Interessanos aqui refletir sobre o contexto em que Castilho José produziu suas versões, bem como oferecer uma análise de sua prática a partir de uma tradução realizada por ele de um epigrama de Marcial. 
Esse poeta latino do século I d.C. é frequentemente associado ao gênero epigramático, uma vez que ele é o principal expoente desse gênero em Roma. Talvez por conta de sua temática bastante ácida e conteúdo baixo Marcial foi deixado à margem do cânone da tradução de textos latinos em contexto lusófono, ao menos até o final do século XX. Considerando essa marginalização do poeta, a surpreendente descoberta de 50 poemas seus vertidos por José Feliciano de Castilho ${ }^{1}$ nos revelou o quanto um estudo sobre a recepção de poesia latina em português se faz necessário, principalmente pelas particularidades de tradução de textos tão polêmicos em pleno século XIX.

No tocante aos estudos de Marcial e sua recepção tivemos contato com o artigo de Pierre Laurens intitulado Traduire Martial, que foi publicado em 1998 na Révue des études latines, em que o professor francês traça uma breve história da recepção de Marcial em seu vernáculo. Laurens parte de um epigrama e analisa diversas traduções, tanto em poesia quanto em prosa, em variados momentos históricos. Neste artigo, nossa resposta brasileira à visada histórica diacrônica como a feita por Laurens, vem sob o ponto de vista sincrônico no sentido em que analisamos traduções de Marcial feitas por um tradutor, Castilho José, em um espaço de tempo determinado, isto é, a segunda metade do século XIX.

Tão importante quanto contextualizar o epigrama de Marcial na obra de Castilho José, é apresentarmos o que nos parece ser sua teorização tradutória. Um bom exemplo da reflexão sobre o fazer tradutório se dá com o próprio Castilho José, em sua anotação dos Amores. No capítulo intitulado "Amores de Ovídio; versão", apresenta-nos informações sobre a obra, sobre a tradução de seu irmão e sobre tradução lato sensu, arte que acredita não ser menos relevante do que produções originais:

[...] Sem aprofundarmos a renhida questão do merito relativo das composições originaes ou traducções, já alhures dissemos que - transportar as riquezas de um idioma para outro, mui diverso de indole e constituição; - apoderar-se, em grau egual, dos mais reconditos segredos de duas linguas, sabendo dissecar as mais tenues fibras de ambas; - incorporar na propria a inteligencia alheia, e d'ahi observar a materia de identico modo; - conhecer como se-foge da fidelidade infiel, que predendo-se ao vocabulo litteral, olvida ser a idéa, neja a palavra que se-traduz; - vedar a si mesmo o impulso natural de desinvolver e incarar o pensamento de um modo peculiar; - luctar com athleta de estylo; rivalisar com victorias do ingenho; - ornar a phrase estranha de vestes e cores nacionaes, tão conchegadas e proprias, que os mais atilados olhos se-enganem; - são meritos relevantes, que podem derramar tanta gloria como producções originaes de subido quilate. (OVIDIO, 1858, p.180-181)

Dessa declaração destacamos especialmente "foge da fidelidade infiel, que predendo-se ao vocabulo litteral olvida ser a idéa", aqui Castilho José evidencia sua opinião sobre uma das questões mais discutidas pelos teóricos de tradução: a fidelidade à obra estrangeira ou a fidelidade à língua de chegada.

\footnotetext{
1 Essas traduções foram encontradas na Grinalda da Arte de Amar que são anotações de Castilho José que comentam e explicam os versos de Ovídio traduzidos por seu irmão Antônio Feliciano de Castilho (1862). Em suas anotações José explica temas, palavras e elementos de cultura latina e para isso se vale de variados autores, tanto da própria Antiguidade Clássica quanto de autores modernos. Trabalhamos com esse corpus desde a Iniciação Científica dentro do projeto de pesquisa "José Feliciano de Castilho e a tradição clássica no séc. XIX”, sob orientação do Prof. Dr. Brunno V. G. Vieira da UNESP-Araraquara, e com apoio da FAPESP.
} 
Desse modo, essa preocupação se aproxima das questões levantadas ainda no séc. XIX, pelo filólogo e tradutor alemão Schleiermacher, autor também retomado por Berman (2002, p.15). Em Über die Verschiedenen Methoden des Übersetzen ("Sobre os diferentes métodos de traduzir") ${ }^{2}$ encontra-se uma ainda moderna reflexão sobre as formas de "levar o autor ao leitor" ou "levar o leitor ao autor", ou seja, deixar o autor mais claro para o leitor, transportá-lo para a língua de chegada numa linguagem palatável à concepção de mundo do leitor, ou fazer com que o leitor entenda a concepção de mundo do autor e se insira nela para a compreensão da obra. Schleiermacher aponta os prós e os contras das duas formas de traduzir, mostrando-nos que talvez um meio termo entre essas duas definições é o que ele chamaria de tradução propriamente dita, ou seja, deixando o texto claro para o leitor, mas sem eliminar suas marcas de estrangeiro. Parece-nos que o tradutor luso-brasileiro prefere que seus poemas estejam vestidos com as cores nacionais e que não se perceba o estrangeiro: "ornar a phrase estranha de vestes e cores nacionaes, tão conchegadas e proprias, que os mais atilados olhos se-enganem" (OVÍDIO, 1858, p. 181), apesar de não descartar o variar entre o literal e o parafrástico, como verificamos na prefação da Arte de Amar:

Foi já posteriormente á leitura d'este poema, que Castilho Antônio se-applicou á já citada Arte de Desamar, com systema totalmente diverso, não tão paráphrase como os Amores, mas também não tão fiel como os Fastos e as Metamorphoses. Entre estas duas obras ha egualmente diversidade de maneira; ha-a nas Epistolas. E é neste variar de Prothèo, hade residir o principal dos méritos do Ovídio portuguez. (OVÍDIO, 1862, p. 37)

Tendo em mente essas concepções tradutórias, optamos por adotar na análise estrutural da tradução castilhiana que apresentaremos a seguir o aparato teórico de Antoine Berman que em seu A tradução e a letra ou o albergue do longínquo (2007), além de tratar sobre tradução etnocêntrica e hipertextual, esquematiza uma "sistemática da deformação" que, segundo ele, é intrínseca à prática tradutória. Ainda que Berman defina esses valores pensando em prosa, como ele apresenta também em seu livro estudos sobre tradução de poesia, arriscaremos uma análise embasada em suas definições à guisa de verificação e experimentação de teorias que possam fundamentar nossos comentários às traduções de nosso corpus.

Apresentaremos para ilustrar nossa aplicação das teorias bermanianas a tradução de Castilho José para o epigrama 71 de Marcial, juntamente com o texto latino da Panckoucke, que era a edição adotada pelo tradutor, a nossa tradução escolar e o texto de Castilho José atualizado e anotado. Para tanto seguiremos a metodologia adotada em nosso trabalho, em que realizamos a tradução escolar do texto latino para que tenhamos uma base para comparação ao texto latino, depois transcrevemos, atualizamos e anotamos o texto de Castilho José. Uma vez estabelecida a tradução, contextualizamos o epigrama de Marcial inserido na anotação de José Feliciano de Castilho para então realizarmos os comentários das escolhas de tradução do autor português.

\footnotetext{
2 Servimo-nos da tradução espanhola: Sobre los diferentes métodos de traducir de Valentín García Yebra (2000).
} 


\section{Marcial, Epigrammata, I, LXXI}

Naevia sex cyathis, septem Justina bibatur; Quinque Lycas, Lyde quatuor, Ida tribus. Omnis ab infuso numeretur amica Falerno; Et quia nulla venit, tu mihi, Somne, veni.

\section{Tradução de serviço}

Que Naevia seja bebida ${ }^{3}$ em seis taças, Justina em sete ${ }^{4}$ Licas em cinco, Lyde em quatro e em três Ida Que toda amante seja contada pelo vinho Falerno derramado E, porque nenhuma veio, tu a mim, Sonho, vem.

\section{Tradução de Castilho José, 1862 (texto atualizado e anotado):}

\section{Evoé $^{5}$}

padre Lieu' ${ }^{6}$ !

Saboé ${ }^{7}$,

grão Bassareu ${ }^{8}$ !

Venha de lá uma saúde prévia;

cinco taças encher quero por Névia.

E vê como esta se empina ${ }^{9}$ sete vezes por Justina.

A Lieu mais quatro;

a Ida mais três.

Tantas letras das moças que idolatro, quantos os copos quero que me dês.

E então! Não viram esta?

Não 'stá bonita a festa?

Já que não vem nenhuma cobrir-me com abraços, vem tu, Morfeu ${ }^{10}$, dest'alma, lançar-te nos meus braços.

\footnotetext{
${ }^{3}$ No Oxford Latin Dictionary (OLD), é encontrada a acepção "brindar", justamente abonada por esse uso de Marcial: "brindar um nome, bebendo tantas vezes quanto forem as letras que o compõem".

${ }^{4}$ Optamos pela transcrição do latim para manter a quantidade de letras evocadas no texto de partida.

${ }^{5}$ Evoé: grito que soltavam as bacantes, invocando Baco nas orgias. (CA)

${ }^{6}$ Lieu: transcrição de Lyaeus, um dos nomes de Baco, que significa "aquele que deixa livre" (OLD).

${ }^{7}$ Saboé: (do grego sabor) interjeição usada pelas Bacantes (BAILLY).

${ }^{8}$ Bassareu: nome de Baco aparentemente tomado da vestimenta de pele de lobo usada pelas bacantes (OLD). Camilo Castelo Branco em $O$ vinho do Porto cita estes primeiros quatro versos de saudação à Baco (1903, p. 17).

${ }^{9}$ Empinar: fazer ressaltar erguendo. (CA)

${ }^{10}$ Morfeu dest'alma: "sonho desta alma"; o tradutor emprega o deus Morfeu, filho do sono e da noite como metonímia para sonho (FARIA, 1994, p 347).
} 


\section{Contexto em que aparece a tradução}

Como o epigrama de Marcial insere-se nas notas de Castilho José para a tradução da Arte de Amar, cabe aqui o contextualizarmos em relação a esse texto, o que nos remete ao verso 245 do primeiro canto da Arte de Amar (et Venus in vinis, ignis in igne fuit.). Esse verso é vertido por Antônio Feliciano assim: "juncta-se fogo a fogo: arde no vinho o amor", trata-se do verso derradeiro de uma estrofe em que Ovídio fala sobre o vinho. Castilho José intitula sua nota de "Bebedeira amorosa. Beber à saúde" e comenta sobre o poder do vinho em "causar alegria e amorosas disposições" (1862, p.137). Percebemos que Castilho José adota certo tom de biografismo ao afirmar que o próprio Marcial, quando bebia quantos copos fossem as letras dos nomes das namoradas, "caia a dormir como um porco, e não ganhava nada" (1862, p.137). Vale ressaltar também a necessidade de verificação do costume de se beber a quantidade de taças conforme o número de letras que há no nome das moças, a fim de melhor entendimento do epigrama. O próprio Oxford Latin Dictionary traz o verbo bibo na acepção de "brindar", abonada justamente pelo uso em Marcial, com a seguinte definição "brindar um nome, bebendo tantas vezes quanto forem as letras que o compõem". Ora, ainda que essa ocorrência só apareça em Marcial, no epigrama 50 do livro 8 fica claro que é um costume romano e não uma mania do poeta, já que ele ordena que o interlocutor beba o número de letras de um nome.

\section{Uma leitura bermaniana}

Sobre a tradução, já de início o que podemos observar da comparação entre o texto de partida e o texto de chegada é o aumento do número de versos, o que Berman chama de "alongamento". Para ele o aumento da extensão do texto se deve a duas características elementares da tradução: a racionalização e a clarificação (2007, p. 51), em poucas palavras, a racionalização na tradução leva do concreto ao abstrato, reordenando linearmente sua estrutura sintática, e a clarificação procura definir o que o texto de partida trabalha com o indefinido. Conforme veremos adiante, nos versos de Castilho José, a grande maioria dos acréscimos estão relacionados a aspectos como rima e metrificação. O alongamento se dá na proporção de dois dísticos elegíacos no texto de partida vertidos em 18 versos portugueses de metros variados.

Considerando a divisão estabelecida no texto de Castilho José, temos o epigrama dividido em três estrofes. Na primeira delas, os cinco primeiros versos caracterizam um acréscimo constituído por uma saudação a Baco, deus do vinho, que não está presente no texto de partida e que, se nos valermos de Berman, poderíamos classificar o como "enobrecimento" na medida em que engrandecer é exatamente o que faz a presença do deus. O primeiro decassílabo dessa estrofe "Venha de lá uma saúde prévia" é acrescentado, aparentemente, para a rima com "Névia", do último verso da estrofe, mas ressalta também a ideia do brinde e do beber à saúde que está presente no poema e no contexto da nota em que está inserido. 
Vale atentar para a adaptação etnocêntrica de Castilho José ao verter os nomes e as quantidades de letras e copos que o eu-lírico beberá por cada mulher, o que no texto de partida está Naevia sex cyathis ("Névia em seis taças") no texto de chegada fica "cinco taças encher quero por Névia", e assim por diante quando diferir o número de letras do latim e do português. $\mathrm{O}$ tradutor apaga a diferença entre as línguas, privilegiando o vernáculo.

A segunda estrofe do texto de chegada refere-se à Justina, o que no texto de partida se dá ainda no primeiro hexâmetro. No primeiro verso dessa estrofe Castilho José acrescenta uma característica de Justina, o que novamente ocorre por conta da rima entre "empina" e "Justina". É interessante notar que esses dois versos em heptassílabos são inseridos justamente quando se brinda sete vezes e podemos enxergar aí uma possível relação entre brindes e sílabas métricas, o que coincidentemente ou não também ocorre no verso seguinte, que fala de Lieu em quatro sílabas métricas.

As personagens de Licas e Lyde são simplesmente suprimidas no texto de chegada em prol da repetição de Lieu, que nos leva a perceber dois elementos bermanianos nessa prática: 1) o primeiro de enobrecimento, uma vez que é remarcada presença do deus (Lieu é um dos nomes de Baco); e 2) por outro lado, como "há desperdício pois tem-se menos significantes na tradução do que no original" (2007, p. 54) verificamos um empobrecimento quantitativo.

Para parafrasear o segundo hexâmetro (omnis ab infuso numeretur amica Falerno) Castilho José utiliza os dois últimos decassílabos da segunda estrofe - o que vertemos em nossa tradução de estudo por "Que toda amante seja contada pelo vinho Falerno derramado" -, na forma de uma explicação no texto de chegada ao que já foi enumerado anteriormente "Tantas letras das moças que idolatro,/ quantos copos quero que me dês". Seguindo o esquema de Berman poderíamos classificar esses versos como "clarificação", mas no que ele chama de sentido negativo que seria: "tornar claro o que não é e não quer ser no original" (2007, p. 51).

Os dois primeiros versos da terceira estrofe são um acréscimo. Não há no texto de partida nenhuma referência a festas, mas sua inserção reforça a ideia de uma grande bebedeira, o que configuraria para Berman em outro empobrecimento quantitativo. Os versos seguintes são paráfrase ao último pentâmetro (Et quia nulla venit, tu mihi, Somne, veni) que traduzimos por "E, porque nenhuma veio, tu a mim, Sonho, vem" e que no texto de chegada está traduzido hipertextualmente no terceiro verso "Já que não vem nenhuma". Essa hipertextualidade é seguida por acréscimos que cumprem o papel de rima e de clarificação "cobrir-me com abraços,/ [...] /lançar-te nos meus braços".

É digna de atenção a utilização do enobrecimento, como chama Berman, causado pela utilização de Morfeu, personagem da Mitologia grecoromana. No texto de partida Marcial personifica somne "Sonho". Na tradução, o fato de Castilho José ter optado por se valer da metonímia e utilizar o deus do sono ressalta a marcação do caráter latino no texto de chegada, o que parece uma compensação para os acréscimos e apagamentos presentes ao longo de sua tradução. 


\section{Conclusão}

A análise, feita sob a perspectiva de Berman, mostra nosso interesse em comentar o texto embasado por um teórico da tradução. Temos em mente que a teorização de Berman, apesar de elucidar nossa leitura, tem como pressuposto uma valorização da versão literal ou hipertextual condizente com as práticas tradutórias mais recentes. O repúdio desse teórico a procedimentos parafrásticos e etnocêntricos se distancia em muito da prática tradutória de Castilho José. No entanto a breve análise apresentada neste artigo faz parte de nossa busca por teorias que auxiliem a realizar um comentário mais consistente. Enquanto Berman parece ter o intuito de estabelecer uma história de "práticas tradutórias boas ou preferíveis", nosso objetivo foi o de oferecer a possibilidade de compreender melhor a prática tradutória de Castilho José.

Joana Junqueira Borges joana.jb@gmail.com

Universidade Estadual de São Paulo (Araraquara) 


\section{Referências bibliográficas}

Aulete, Caldas. Aulete Digital - Dicionário contemporâneo da língua portuguesa: Dicionário Caldas Aulete, Lexikon, 2007. Acessado em 8 de outubro de 2009. Disponível: http://www.auletedigital.com.br/

Berman, A. A tradução e a letra ou o albergue do longínquo. Tradução de Marie-Hélène C. Torres, Mauri Furlan e Andréia Guerini. Rio de Janeiro: 7Letras, 2007.

CAmpos, H. "Tradução, ideologia e história". In: SimOn, Iuma Maria (org.) Território da Tradução, revista Remate de Males. Campinas: IEL, 1984. p. 239-247.

Glare, P. G. W. Oxford Latin dictionary. Oxford: Clarendon Press, 1982.

Homero. Odisséia. Tradução de Manuel Odorico Mendes, edição de Antônio Medina Rodrigues. São Paulo: Edusp, 1992.

LAurens, P. “Traduire Martial”. Révue des études latines. p.200-215, 1998.

Martial. Epigrammes de M. Val. Martial. Ed. V. Verger, N. A. Dubois et J. Mangeart. Paris: Panckoucke, 1834.

Martialis, M. V. Epigrammata. Oxford Classical Texts. 2007

OvíDIO. Arte de amar de Publio Ovidio Nasão. Tradução de A. F. de Castilho seguidas de comentários de J. F. de Castilho. 3 Tomos. Rio de Janeiro: Laemmert, 1862.

. Os amores de P. Ovídio Nasão. Paráfrase por Antonio Feliciano de Castilho, seguida pela Grinalda Ovidiana, por José Feliciano de Castilho. 11 volumes. Rio de Janeiro: Bernardo Xavier Pinto de Sousa, 1858 .

. Metamorfoses. Tradução de: Bocage, introdução e edição de J. A. Oliva Neto. São Paulo: Hedra, 2007.

Virgílio. Bucólicas. Tradução de: M. O. Mendes. Ed. anotada e comentada pelo Grupo de Trabalho Odorico Mendes. Cotia (SP): Ateliê Editorial; Campinas (SP): Editora da Unicamp, 2008a.

. Eneida. Tradução de: J. V. Barreto Feio e J. M. da Costa e Silva. Introdução e edição de P. S. Vasconcellos. São Paulo: Martins Fontes, 2004.

. Eneida brasileira: tradução poética da epopeia de Públio Virgílio Maro. Org. P. S. Vasconcellos et al. Tradução de M. O. Mendes. Campinas: Editora da Unicamp, 2008 b. 